\title{
DEVELOPMENT OF MANUAL DEXTERITY IN PRESCHOOL CHILDREN
}

original paper

(1) University School of Physical Education in Wroclaw

DOI: https://doi.org/10.5114/hm.2018.79735

\section{KAMILA CZAJKA, MAŁGORZATA KOŁODZIEJ, KATARZYNA KOCHAN, TERESA SŁAWIŃSKA}

Department of Biostructure, Faculty of Physical Education, University School of Physical Education in Wroclaw, Wroclaw, Poland

\begin{abstract}
Purpose. The aim of the study is to identify the changes in manual dexterity that occur in preschool children.

Methods. The sample consisted of 79 healthy preschool children from Wroclaw, Poland. Manual dexterity was assessed twice: at the beginning of the school year and 9 months later at the end. The mean age of the group was $5.98 \pm 0.45$ years (initial assessment) and $6.86 \pm 0.35$ years (final assessment). Motor performance was evaluated with the Motorische Leistungsserie (MLS) test. Statistical analysis was carried out with ANOVA, and the percentage change of each parameter was calculated for the 9-month study period. Differences were considered significant at $p<0.05$.

Results. There was a $45 \%$ improvement in steadiness, which shows that the children were more able to hold their hands in a given position without shaking for a prolonged time. The children made significant progress in grasping and carrying small objects with fingers and placing them in sequential openings on the work surface of the test apparatus in a vertical line, performing better than adults in this regard. The results for the aiming subtest improved by over $20 \%$ in the children examined. The rate of tapping increased by almost $8 \%$. Improvements in line tracing, however, were limited to the accuracy of performing the subtest.
\end{abstract}

Conclusions. The results of the study reveal the need for longitudinal studies on this topic. Selected parameters of manual dexterity in preschool children improved from $4 \%$ to $45 \%$ over the course of the 9-month school year.

Key words: preschool children, development, hand function, manual dexterity, MLS (Motorische Leistungsserie)

\section{Introduction}

The development of manual dexterity, like the development of motor skills in the whole body, is intimately related to the development of the nervous system. This process is long and very complex, as the part of the motor cerebral cortex that is responsible for the hands is much larger than that for the other parts of the body.

During the preschool years, children make progress in gross motor skills such as running, jumping, balancing. Their movement becomes more controlled and learning ability also begins to increase. Children of this age develop upper body mobility. As a result, their throwing and catching abilities improve in speed and accu- racy. The main stages of the development of grasping have already been completed [1]. Further changes in manual dexterity take place, which make it possible to acquire the new skills necessary to independently perform a wide range of activities. Dressing oneself, for example, requires fine hand motions to fasten buttons, close zippers, and tie shoes. Eating requires the coordinated use of knives, forks and spoons. Manual dexterity is also essential for taking part in preschool activities, during which a wide range of materials are used, including scissors, crayons, and markers.

Between 3 and 6 years of age, the wrist becomes stabilized on the internal aspect. This allows children to start performing activities that prepare them for writing,

Correspondence address: Kamila Czajka, Department of Biostructure, Faculty of Physical Education, University School of Physical Education in Wroclaw, al. I.J. Paderewskiego 35, 51-612 Wroclaw, Poland, e-mail: kamila.czajka@awf.wroc.pl

Received: August 29, 2018

Accepted for publication: November 17, 2018

Citation: Czajka K, Kołodziej M, Kochan K, Sławińska T. Development of manual dexterity in preschool children. Hum Mov. 2018;19(4):79-86; doi: https://doi.org/10.5114/hm.2018.79735. 
K. Czajka, M. Kołodziej, K. Kochan, T. Sławińska, Development of manual dexterity in preschool children

one of the most important skills in the first years of primary school [1, 2]. Primary school activities involve manual dexterity to an even higher degree $[3,4]$.

In primary school, $30-60 \%$ of time is dedicated to learning writing and other manipulative tasks [3]. Therefore, the main goal during the preschool and elementary school periods should be to facilitate the development of a wide range of manual activities. Yakimishyn and Magill-Evans [5] maintain that the preschool period is especially important for the formation of the fundamental manipulative abilities required in elementary school. They encourage teachers to monitor the development of manual dexterity during exercises involving various implements [5, 6].

Overcoming problems with penmanship helps children acquire knowledge during the first years of elementary school and improves academic success in later years $[7,8]$. A positive transition from preschool to elementary school and early success in dealing with the obligations of elementary school open the door to future social and educational competence [9].

Proper development of manual dexterity is associated with many aspects of general childhood development, including perception, socialization, and emotional maturation [10-13]. In most cases, there are difficulties with performing particular tasks requiring manual dexterity during early childhood. Most often, these are transitory and do not indicate that any serious problem exists. In order to create the right conditions for optimal childhood development, however, the development of manual dexterity should be carefully monitored. This allows teachers to plan activities effectively, and to intervene at an early stage should the need arise. Monitoring is also a basic tool to evaluate progress in attaining desired objectives on schedule.

While the literature concerning handwriting readiness and fine motor skills in children is abundant [4, 14-18], little is known about age-related changes related to children's manual dexterity parameters. Some methods have been created to assess children's fine motor skills [6, 14, 16-18], but none of these instruments includes all necessary components to evaluate different aspects of manual dexterity parameters [17].

The Motorische Leistungsserie (MLS) (Motor Performance Series) test, included in the Vienna Test System, measures different hand functions; research has already been carried out among adults and seniors [19-22], although so far there have been no reports concerning any healthy population of children.

The aim of the present study is to identify the changes in manual dexterity parameters that occur in preschool children.

\section{Material and methods}

\section{Participants}

The sample consisted of 79 healthy preschool children from Wrocław, Poland (43 boys and 36 girls). All public kindergartens in the Wrocław downtown were informed, via the phone and leaflets, about the test procedure and the use of the results. The children's parents were given leaflets with detailed description of the measurement. The children were all in the final year of preschool, and were being prepared to begin studying in elementary school. Manual dexterity was assessed twice: at the beginning of the school year, and at the end, 9 months later. Because the results of manual dexterity testing did not significantly differ between boys and girls, they were treated as a single group for the purposes of this study. The mean age of the group was $5.98 \pm 0.45$ years during the initial assessment and $6.86 \pm 0.35$ years during the final assessment. The children were tested at the Laboratory for Biokinetics of the University School of Physical Education in Wroclaw. The laboratory is certified in accordance with ISO 9001:2001 quality standards.

\section{Measures}

Motor performance was evaluated with the MLS test, belonging to the Vienna Test System (SCHUHFRIED GmbH, Austria). Version 6.03.004 of the program was applied in all analyses.

The MLS test is carried out with the use of a computerized apparatus designed to accurately analyse factors associated with manual dexterity. The apparatus consists of a work surface $(300 \times 300 \times 15 \mathrm{~mm})$, which can be used in both horizontal and vertical orientations (Figure 1). The surface contains holes of different diameters for steadiness, a groove with several bends and angles for line-tracing, contact points for aiming, and two small metal plates for tapping. On each side of the work surface is a contact pencil, one for the left hand, and the other for the right. These are used to measure time or keep track of the number of errors, and operate by closing a circuit with a potential of $5 \mathrm{~V}$ and a current of $20 \mathrm{~mA}$.

All subtests were carried out for both the right and the left hand. The subject sat in front of the work surface and performed the series of MLS subtests, starting with the right hand. Subjects were not permitted to rest their forearms anywhere during the test.

The MLS test consists of 5 subtests: (1) steadiness, (2) line tracing, (3) aiming, (4) tapping, (5) long peg 
board; these are designed to measure fine and precise movements of the hand and forearm.

Steadiness is a measure of the ability to place a hand in a certain position and keep it still for a certain time. The subject was instructed to place an electronic pen in a small opening with a diameter of $12 \mathrm{~mm}$ and hold it there without touching the walls of the opening for 32 seconds without supporting the forearm anywhere to steady it. The result recorded represents the number of errors, meaning the number of times the pen comes in contact with the wall of the opening.

Line tracing is a measure of the ability to perform precise arm/hand movements. The subject was instructed to guide an electric pen perpendicular to the plane of the work surface along a groove that changes direction. The results recorded represent the number of errors, meaning the number of times the pen comes in contact with the wall of the groove, as well as the total time required to perform the task. The time of the errors was also recorded.

Aiming is a measure of the ability to perform rapid hand movements while precisely touching small targets. The subject was instructed to sequentially acti- vate 20 round contact plates with a diameter of $5 \mathrm{~mm}$ spaced $9 \mathrm{~mm}$ apart in a vertical column. The results recorded represent the number of errors, that is, the number of times the pen misses the contact plates, as well as the total time required to perform the task.

Tapping is a measure of the ability to perform rapid repetitive hand movements. The subject was instructed to tap an electronic pen on a contact plate with an area of $40 \times 40 \mathrm{~mm}$ as often as possible in 32 seconds. The result recorded represents the total number of taps.

Long peg board is a measure of manual dexterity and the ability to grasp. The subject was instructed to place 25 long pegs with a length of $50 \mathrm{~mm}$ and a diameter of $2 \mathrm{~mm}$ into openings placed vertically on the work surface, starting from the top and moving sequentially to the bottom. The pegs were picked up from a box placed $10 \mathrm{~cm}$ from the edge of the work surface. The result recorded represents the total time required to perform the task.

Hand dominance was recorded on the basis of information supplied by parents and preschool teachers before the test and verified by the technician carrying out the test. Dominance was therefore confirmed by
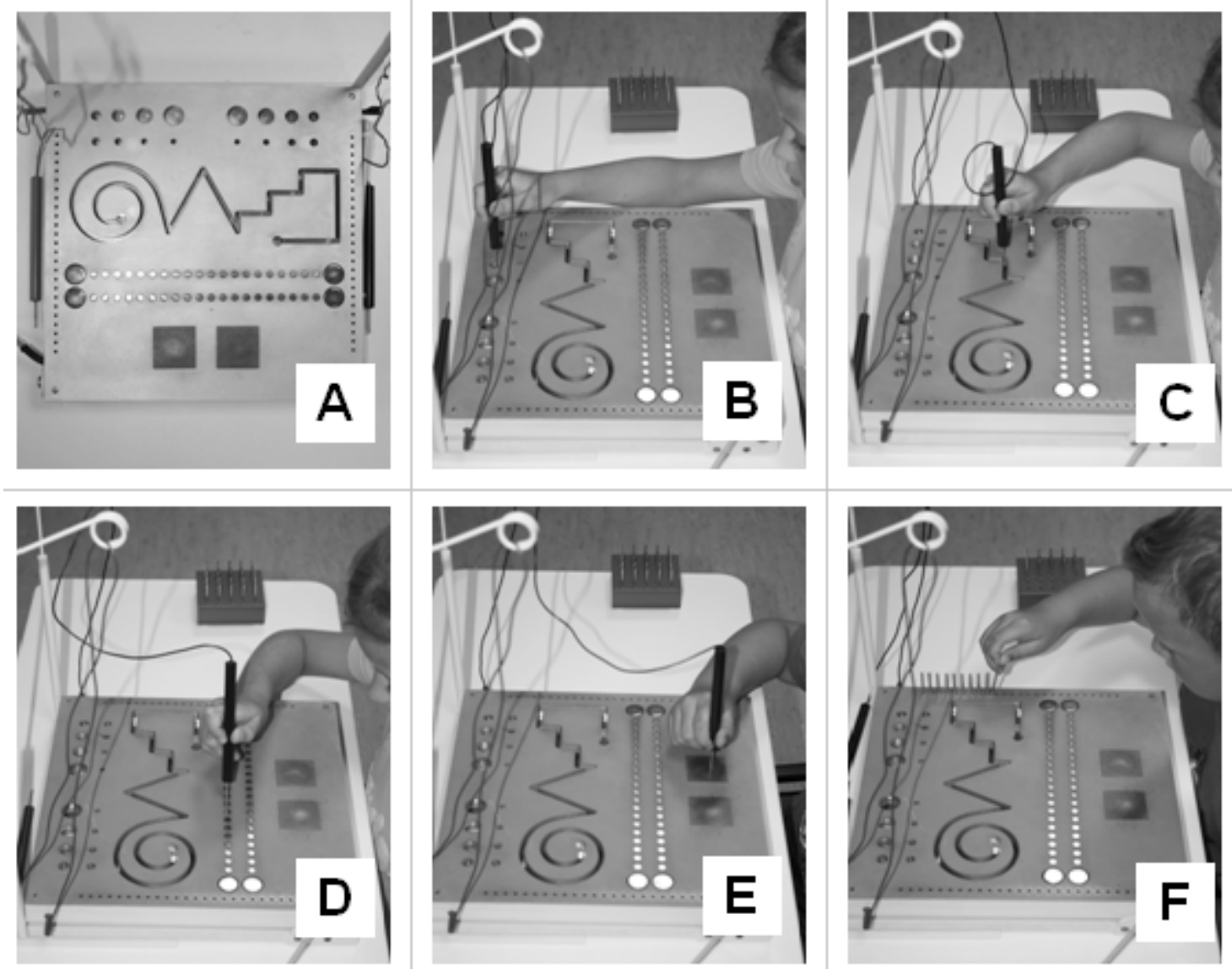

Figure 1. The working platform for the Motorische Leistungsserie (MLS) test and examination of fine motor skills. (A) The MLS work board, (B) steadiness, (C) line tracing, (D) aiming, (E) tapping, (F) long peg board 
K. Czajka, M. Kołodziej, K. Kochan, T. Sławińska, Development of manual dexterity in preschool children

3 independent observers; $91.1 \%$ of the subjects were right-handed. The MLS subtests were performed separately with the dominant and non-dominant hands.

\section{Statistical analysis}

All statistical analyses were carried out with the StatSoft Statistica software package, version 9.0. For each parameter, the arithmetic mean, median, and standard deviation were calculated, and the observed minimum and maximum values were reported. The percentage improvement during the 9-month school year was also calculated for each parameter. The significance of the differences between the initial and final assessments was evaluated with the use of one-way analysis of variance (ANOVA). Differences were considered significant at $p<0.05$.

\section{Ethical approval}

The research related to human use has been complied with all the relevant national regulations and institutional policies, has followed the tenets of the Declaration of Helsinki, and has been approved by the Ethics Committee of the University School of Physical Education in Wroclaw.

\section{Informed consent}

Informed consent has been obtained from the legal guardians of all individuals included in this study.

\section{Results}

The examined children came from families in which most parents had attained tertiary education, with $91.3 \%$ of the mothers and $84.2 \%$ of the fathers having done so. The remaining parents had all completed secondary education. Overall, $17.7 \%$ of the children had two or more siblings, $46.8 \%$ had one sibling, and $35.5 \%$ were only children.

Body height and body mass were significantly higher during the final assessment than at the initial as- sessment 9 months earlier, which is typical at this stage of development. There was no significant difference in the body mass index (BMI) (Table 1).

The mean time for completing the entire MLS test was $10.5 \pm 1.36$ minutes during the initial assessment and $10.2 \pm 2.72$ minutes during the final assessment. This includes the time required to complete each subtest, as well as the time needed to instruct the children about how to perform each task. For most tasks, results were generally better during the final assessment than during the initial assessment (Figures 2 and 3; Table 2).

The greatest improvement for both hands was seen in the steadiness subtest, for which the percentage improvement was $43-45 \%$ (Figures 2 and 3 ). The number of errors for this task decreased with age (dominant hand: $F=6.89, p<0.01$; non-dominant hand: $F=$ $11.25, p<0.01$ ).

There was also a significant improvement in both hands for aiming, tapping, and the long peg board (Table 2). For aiming, the number of errors decreased by $22-24 \%$, and the time required to perform the test decreased by $7-14 \%$. However, only the difference in the number of errors for the non-dominant hand was statistically significant $(F=6.30, p<0.05)$.

For line tracing, the time spent in making errors decreased significantly for the dominant hand, whereas there was no significant difference in the total number of errors or in the total time needed to perform the task. All in all, arm-hand movement was more precise in the dominant hand. For the non-dominant hand, results were mixed. There was a significant increase in the number of errors and in the time required to perform the task (Table 2).

For most subtests, the results improved in 40-90\% of the children during the school year. In the remaining children, lack of improvement was generally seen in the number of errors per subtest. Any decreases in performance were insignificant and can be attributed to the stabilization of selected test parameters.

Table 1. Body height, body mass, and BMI for the initial and final assessments

\begin{tabular}{|c|c|c|c|c|c|c|c|c|c|}
\hline \multirow{2}{*}{ Somatic parameters } & \multicolumn{4}{|c|}{ Initial assessment } & \multicolumn{4}{|c|}{ Final assessment } & \multirow{2}{*}{$p$} \\
\hline & Mean & $S D$ & Min & Max & Mean & $S D$ & Min & Max & \\
\hline Body height (cm) & 119.0 & 5.64 & 105.8 & 133.7 & 123.1 & 5.84 & 109.4 & 138.0 & $0.0001^{*}$ \\
\hline Body mass (kg) & 22.4 & 3.75 & 16.6 & 34.4 & 24.5 & 4.36 & 17.1 & 37.4 & $0.0014^{*}$ \\
\hline $\mathrm{BMI}\left(\mathrm{kg} / \mathrm{m}^{2}\right)$ & 15.7 & 1.79 & 13.1 & 22.1 & 16.0 & 1.91 & 13.4 & 22.1 & 0.2534 \\
\hline
\end{tabular}

BMI - body mass index

* statistically significant differences $(p<0.05)$ 


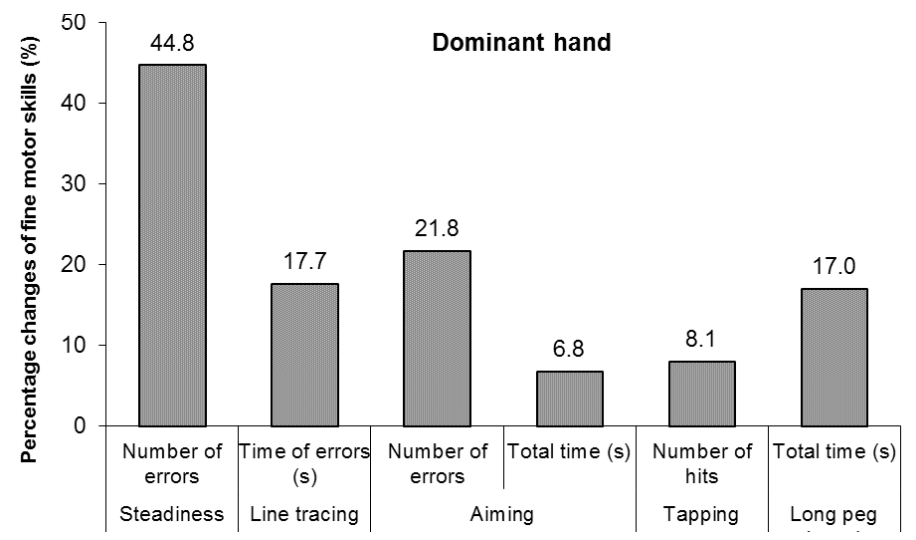

Figure 2. Percentage improvement in performance for the dominant hand during the 9-month-long school year

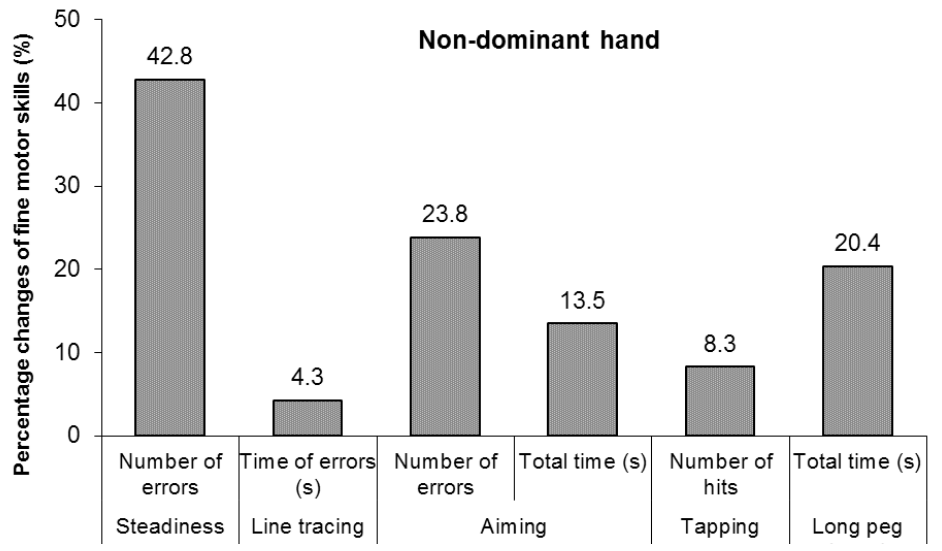

Figure 3. Percentage improvement in performance for the non-dominant hand during the 9-month-long school year

Table 2. Results of ANOVA for changes in the Motorische Leistungsserie (MLS) test parameters for the dominant and non-dominant hands during the 9-month-long school year

\begin{tabular}{|c|c|c|c|c|c|c|}
\hline \multirow{2}{*}{ Hand } & \multirow{2}{*}{ Task } & \multirow{2}{*}{ Parameter } & Initial assessment & \multicolumn{3}{|l|}{ Final assessment } \\
\hline & & & Mean $(S D)$ & Mean $(S D)$ & $F$ & $p$ \\
\hline \multirow{8}{*}{ Dominant } & Steadiness & Number of errors & $3.51(4.23)$ & $1.94(3.22)$ & 6.893 & $0.010 *$ \\
\hline & Line tracing & Number of errors & $46.50(14.17)$ & 46.7 (13.75) & 0.009 & 0.922 \\
\hline & & Time of errors (s) & $6.31(2.90)$ & $5.19(2.20)$ & 7.395 & 0.007 * \\
\hline & & Total time (s) & $26.59(9.84)$ & $28.31(8.78)$ & 1.341 & 0.249 \\
\hline & Aiming & Number of errors & $4.24(3.71)$ & 3.32 (3.27) & 2.755 & 0.099 \\
\hline & & Total time (s) & $14.72(3.38)$ & $13.71(3.54)$ & 3.300 & 0.071 \\
\hline & Tapping & Number of hits & 123.57 (15.48) & 133.57 (16.02) & 15.916 & $0.001 *$ \\
\hline & Long peg board & Total time (s) & $72.92(10.22)$ & $60.49(8.25)$ & 70.819 & $0.001 *$ \\
\hline \multirow{8}{*}{ Non-dominant } & Steadiness & Number of errors & $9.08(8.44)$ & $5.19(5.90)$ & 11.255 & $0.001 *$ \\
\hline & Line tracing & Number of errors & 43.42 (18.18) & 50.77 (13.86) & 8.177 & $0.005^{*}$ \\
\hline & & Time of errors (s) & $6.65(2.19)$ & $6.36(2.23)$ & 0.672 & 0.414 \\
\hline & & Total time (s) & $20.76(8.27)$ & $24.76(8.01)$ & 9.556 & $0.002 *$ \\
\hline & Aiming & Number of errors & $10.99(7.57)$ & 8.37 (5.37) & 6.300 & $0.013^{*}$ \\
\hline & & Total time (s) & $17.43(5.43)$ & $15.07(4.0)$ & 1.881 & 0.172 \\
\hline & Tapping & Number of hits & $105.52(15.49)$ & 114.29 (16.09) & 12.192 & $0.001 *$ \\
\hline & Long peg board & Total time (s) & $84.04(14.32)$ & 66.87 (9.83) & 77.173 & $0.001 *$ \\
\hline
\end{tabular}

* statistically significant differences $(p<0.05)$ 
K. Czajka, M. Kołodziej, K. Kochan, T. Sławińska, Development of manual dexterity in preschool children

\section{Discussion}

The development of manual dexterity is vital for overall development. Manual dexterity develops during early childhood in accordance with a predictable course of events, although the pace varies from child to child [1].

The present study revealed a significant improvement in manual dexterity among preschool children during the 9-month-long school year. There was a $45 \%$ improvement in steadiness, which shows that the children were more able to hold their hands in a given position without shaking for a prolonged time.

An increase in steadiness during childhood development was also observed in studies carried out among schoolchildren aged 6-16 years from Spain and those aged 7.5-11 years from the Netherlands [23, 24]. There have not, however, been any previous reports on decreased shaking in children of preschool age but increase in tremor amplitude occurs in all adults (18-60 years) [25].

Mild hand tremor may provide valuable information about the state of development of the nervous system in young children, which makes it worthwhile to monitor this phenomenon. The authors of the Spanish and Dutch studies mentioned above point out that physiological tremor is associated with difficulties in acquiring competence in handwriting. However, they measured involuntary tremor during drawing a line in an Archimedean spiral.

The line tracing subtest used in the present study also detects hand tremor. There was less improvement in performance for line tracing than for the other MLS subtests. This indicates that there was little improvement in performing precise arm-hand movements while changing the axis of motion. Combining hand motion with the motion of the wrists enhances the function of the hand, but is difficult to coordinate at the age of 6 .

There was an improvement in accuracy in performing the line tracing subtest with the dominant hand. During the final assessment, the number of errors and the total time required to perform the task remained essentially the same as during the initial assessment. There was, however, a significant decrease in the amount of time spent in making errors, which indicates that control over precision improved for this task.

The line tracing subtest requires smooth and accurate hand motions, similar to those performed during handwriting. This skill is acquired during elementary school, which may explain why there was little improvement in this task among the preschool children examined in the present study. Many studies deal with the many factors involved in handwriting, such as kinaesthesia, motor planning, eye-hand coordination, visuomotor integration, and in-hand manipulation [2].

Encouraging children to participate in activities that promote the development of the hand muscles needed to correctly hold a pencil is of great importance during the preschool years. Yakimishyn and Magill-Evans [5] believe that the basics of manipulating various classroom implements should be practiced in early childhood. They suggest that the proper development of hand function can be improved by having children use a variety of implements of different sizes, such as markers, crayons, or pencils, and by having them practice drawing on surfaces of different inclinations. Problems with handwriting are observed in 10-30\% of schoolchildren [26]. The steadiness and line tracing subtests may be used for timely diagnosis of such issues.

The results of the present study indicate that preschool children make significant progress in grasping and carrying small objects with the fingers and placing them in sequential openings on the work surface of the test apparatus in a vertical line. This ability has not been previously studied in children, but similar results have been observed in adults. In a study of healthy adults aged $30-50$ years, the results for the long peg board subtest averaged $67.8 \pm 10.4$ seconds for the right hand and $67.9 \pm 10.2$ seconds for the left hand [19]. The results achieved by the preschool children in the present study were better than those for the adults in the aforementioned study, with $60.5 \pm 8.3$ seconds for the dominant hand and $66.9 \pm 9.8$ seconds for the non-dominant hand. This may be due to the fact that hand and finger dexterity in the children may have been stimulated by playtime activities and tasks that require the use of hands during early childhood.

The results for the aiming subtest improved by over $20 \%$ in the children examined. The subjects performed the subtest slower and with a greater number of errors than the adults in the aforementioned study. The time required to perform the task with the dominant had was $13.7 \pm 3.5$ seconds for the children and $8.7 \pm$ 1.8 seconds for the adults. The number of errors equalled $3.3 \pm 3.3$ for the children and $0.3 \pm 0.8$ for the adults. The results for adults in the aforementioned study were similar to those for the aiming subtest obtained in another study among adults aged $25-50$ years [20].

The fundamental changes observed in the preschool children over the 9-month-long school year suggest that their skill at aiming will improve dynamically in the near future.

In the short time covered by the present study, there was also an $8 \%$ improvement in the mean results for 
the tapping subtest per 32 seconds: from 124 to 134 taps for the dominant hand and from 106 to 114 for the second, non-dominant hand. In adults aged 25-50 years, the number of taps was 210 for the right hand and 185 for the left. In adults aged 70-80 years old, the results ranged from about 140 to 160 taps [20]. Taking into account the pace of change observed in the children, they can be expected to tap at a higher rate than the adults within 2-3 years.

The rate at which manual dexterity develops increases not only with age, but also with continuous practice and experience. The use of hands in preschool and elementary school activities can be monitored to systematically assess the development of manual dexterity and detect children that deviate significantly from the norm. Early diagnosis makes it possible to implement proper techniques to promote proper development of manual dexterity and to compensate for deficits in hand function. Furthermore, comparing the results of studies in different age groups reveals that further research is needed on the ontogeny of manual dexterity both during childhood and during old age. Standardized testing of manual skills has been proposed both to expand our knowledge of the complexity of manual skills and to identify the factors associated with manual dexterity for diagnostic purposes [12].

\section{Conclusions}

Our findings have illustrated the changes in children's manual dexterity associated with age, but the research had some limitations. Firstly, the participating children represented different social groups, but they came from one large city; thus, they are not representative of the whole population of Poland.

Secondly, as it turned out difficult to find any research on healthy children carried out by use of the computer-based test of the Vienna Test System (MLS), it was impossible to compare our results with other groups in Poland and in the world.

The results of the present study provide important information on the pace of changes in preschool children's manual dexterity and reveal the need for longitudinal studies on this topic. The main conclusions can be summarized as follows:

1. Selected parameters of manual dexterity improved by $4-45 \%$ over the course of the 9 -month-long school year. The greatest improvement for both hands, by about $45 \%$, was seen in the steadiness subtest. Hand tremor may provide valuable information about the state of the nervous system development in young children and competence in handwriting, which makes it worthwhile to monitor this parameter.

2. In order to minimize problems with handwriting and to promote early success in elementary school, hand function should be systematically monitored in preschool children. The MLS test is a very interesting tool for verifying different hand functions not only in adults and seniors but also in children.

\section{Disclosure statement}

No author has any financial interest or received any financial benefit from this research.

\section{Conflict of interest}

The authors state no conflict of interest.

\section{References}

1. Edwards SJ, Buckland DJ, McCoy-Powlen JD. Developmental and functional hand grasps. Thorofare: SLACK Incorporated; 2002.

2. Cornhill H, Case-Smith J. Factors that relate to good and poor handwriting. Am J Occup Ther. 1996;50(9): 732-739; doi: 10.5014/ajot.50.9.732.

3. McHale K, Cermak SA. Fine motor activities in elementary school: preliminary findings and provisional implications for children with fine motor problems. Am J Occup Ther. 1992;46(10):898-903; doi: 10.5014/ ajot.46.10.898.

4. Marr D, Cermak S, Cohn ES, Henderson A. Fine motor activities in Head Start and kindergarten classrooms. Am J Occup Ther. 2003;57(5):550-557; doi: 10.5014/ajot.57.5.550.

5. Yakimishyn JE, Magill-Evans J. Comparisons among tools, surface orientation, and pencil grasp for children 23 months of age. Am J Occup Ther. 2002;56(5):564572; doi: 10.5014/ajot.56.5.564.

6. Pont K, Wallen M, Bundy A, Case-Smith J. Reliability and validity of the Test of In-Hand Manipulation in children ages 5 to 6 years. Am J Occup Ther. 2008; 62(4):384-392; doi: 10.5014/ajot.62.4.384.

7. Rimm-Kaufmann SE, Pianta RC. An ecological perspective on the transition to kindergarten: a theoretical framework to guide empirical research. J Appl Dev Psychol. 2000;21(5):491-511; doi: 10.1016/S01933973(00)00051-4.

8. Ratzon NZ, Efraim D, Bart O. A short-term graphomotor program for improving writing readiness skills of first-grade students. Am J Occup Ther. 2007;61(4): 399-405; doi: 10.5014/ajot.61.4.399.

9. Bart O, Hajami D, Bar-Haim Y. Predicting school adjustment from motor abilities in kindergarten. Inf Child Dev. 2007;16(6):597-615; doi: 10.1002/icd.514.

10. Owen SE, McKinlay IA. Motor difficulties in children with developmental disorders of speech and language. Child Care Health Dev. 1997;23(4):315-325; doi: 10.1046/j.1365-2214.1997.864864.x. 


\section{HUMAN MOVEMENT}

K. Czajka, M. Kołodziej, K. Kochan, T. Sławińska, Development of manual dexterity in preschool children

11. Case-Smith J. Effectiveness of school-based occupational therapy intervention on handwriting. Am J Occup Ther. 2002;56(1):17-25; doi: 10.5014/ajot.56.1.17.

12. Chien CW, Brown T, McDonald R. A framework of children's hand skills for assessment and intervention. Child Care Health Dev. 2009;35(6):873-884; doi: 10.1111/j.1365-2214.2009.01002.x.

13. Hill EL, Khanem F. The development of hand preference in children: the effect of task demands and links with manual dexterity. Brain Cogn. 2009;71(2):99107; doi: 10.1016/j.bandc.2009.04.006.

14. Smith YA, Hong E, Presson C. Normative and validation studies of the Nine-hole Peg Test with children. Percept Mot Skills. 2000;90(3 Pt 1):823-843; doi: 10.2466/ pms.2000.90.3.823.

15. Feder KP, Mainemer A, Bourbonnais D, Platt R, Blayney M, Synnes A. Handwriting performance in preterm children compared with term peers at age 6 to 7 years. Dev Med Child Neurol. 2005;47(3):163-170; doi: 10.1111/j.1469-8749.2005.tb01110.x.

16. Deitz JC, Kartin D, Kopp K. Review of the BruininksOseretsky Test of Motor Proficiency, Second Edition (BOT-2). Phys Occup Ther Pediatr. 2007;27(4):87-102; doi: 10.1080/J006v27n04_06.

17. Van Hartingsveldt MJ, De Groot IJ, Aarts PB, NijhuisVan Der Sanden MWG. Standardized tests of handwriting readiness: a systematic review of the literature. Dev Med Child Neurol. 2011;53(6):506-515; doi: 10.1111/j.1469-8749.2010.03895.x.

18. Chien CW, Brown T, McDonald R. Examining construct validity of a new naturalistic observational assessment of hand skills for preschool- and school-age children. Aust Occup Ther J. 2012;59(2):108-120; doi: 10.1111/j.1440-1630.2012.00997.x.

19. Zupanic M, Demes P, Seeber A. Psychomotor performance and subjective symptoms at low level toluene exposure. Occup Environ Med. 2002;59(4):263-268; doi:_10.1136/oem.59.4.263.

20. Kalisch T, Wilimzig C, Kleibel N, Tegenthoff M, Dinse HR. Age-related attenuation of dominant hand superiority. PLoS One. 2006;1:e90; doi: 10.1371/journal. pone.0000090.

21. Sebastjan A, Skrzek A, Ignasiak Z, Sławińska T. Agerelated changes in hand dominance and functional asymmetry in older adults. PLoS One. 2017;12(5): e0177845; doi: 10.1371/journal.pone.0177845.

22. Sebastjan A, Skrzek A, Ignasiak Z, Sławińska T. The effects of age and sex on hand movement structure. Aging Clin Exp Res. 2017;29(6):1221-1229; doi: 10.1007/s40520-017-0758-z.

23. Louis ED, Cubo E, Trejo-Gabriel-Galán JM, Villaverde VA, Benito VD, Velasco SS, et al. Tremor in schoolaged children: a cross-sectional study of tremor in 819 boys and girls in Burgos, Spain. Neuroepidemiology. 2011;37(2):90-95; doi: 10.1159/000330352.

24. Smits-Engelsman BC, Van Galen GP. Dysgraphia in children: lasting psychomotor deficiency or transient developmental delay? J Exp Child Psychol. 1997;67(2): 164-184; doi: 10.1006/jecp.1997.2400.

25. Louis ED, Hafeman D, Parvez F, Liu X, Alcalay RN, Islam T, et al. Tremor severity and age: a cross-sectional, population-based study of 2,524 young and midlife normal adults. Mov Disord. 2011;26(8):1515-1520; doi: 10.1002/mds.23674.

26. Feder KP, Mainemer A. Handwriting development, competency, and intervention. Dev Med Child Neurol. 2007;49(4):312-317; doi: 10.1111/j.1469-8749.2007. 00312.x. 